\title{
Os pressupostos da avaliação e a produção de currículos na escola: reflexões a partir da geografia
}

\author{
Daniel Luiz Stefenon ${ }^{1}$ \\ ORCID: 0000-0002-8208-5997 \\ Sonia Maria Vanzella Castellar ${ }^{2}$ \\ ORCID: 0000-0002-6071-748X
}

\section{Resumo}

Ao considerar que a avaliação das aprendizagens tem um papel importante na gestão e na promoção do desenvolvimento intelectual dos estudantes, este trabalho busca apresentar e discutir esse papel a partir do viés dos conhecimentos veiculados pelos discursos pedagógicos em diferentes contextos de realização. Em outras palavras, pretendese refletir acerca da avaliação a partir de suas implicações no âmbito curricular e na construção dos conhecimentos na escola. Além de produções de autores que pensam o conhecimento na escola a partir de sua conexão com fatores que lhe são extrínsecos, ou seja, com o conjunto das contradições sociais que caracterizam os espaços de vivência dos sujeitos que a frequentam, serão também trazidas para o debate reflexões que resultaram de uma pesquisa de doutorado que explorou a relação entre a recontextualização dos saberes disciplinares em diferentes contextos escolares e a (re)produção das desigualdades educacionais. 0 texto demonstra que a definição dos critérios de avaliação incide sobre a conformação dos currículos que se realizam, efetivamente, na escola. Além disso, as expectativas de futuro compartilhadas e o contexto primário de socialização dos estudantes também demonstram potencial de interferência sobre as escolhas realizadas pelo professor no encaminhamento de suas práticas. Por fım, propõe-se uma perspectiva de avaliação em que parâmetros e critérios tenham caráter explícito, mas que sejam conduzidos a partir de diferentes canais e linguagens de comunicação. A partir disso, espera-se contribuir na construção de fundamentos de uma escola que esteja atenta tanto ao reconhecimento e valorização das diferenças, como também à mitigação das desigualdades de acesso aos conhecimentos social e historicamente produzidos.

\section{Palavras-chave}

Avaliação - Currículo - Conhecimento escolar - Ensino de geografia.

1- Universidade Estadual do Centro-Oeste, Unicentro. Irati, Paraná, Brasil. Contato: unicentro.daniel@gmail.com.

2- Universidade de São Paulo, USP. São Paulo, São Paulo, Brasil. Contato: smvc@usp.br. 


\section{The premises of the evaluation process and the production of school curricula: some reflections based on Geography*}

\section{Abstract}

Considering that the evaluation of apprenticeship plays an important role in the management and promotion of students' intellectual development, this paper aims to present and discuss this role based upon the knowledge transmitted through pedagogical practices in different contexts. In other words, we aim to discuss the evaluation process and its implications on the school curriculum and the building of knowledge in school. This debate will be composed by the output of authors who establish a link between knowledge at school and the factors that are extrinsic to this environment, that is, the mix of social contradictions that characterize the school areas where students and teachers interact, as well as by considerations that derive from a doctoral research that looked into the relationship between the recontextualization of the disciplinary knowledge in different school contexts and the reproduction of educational inequalities. In this article, we show that the definition of evaluation criteria has an impact on the elaboration of the curriculum that is actually followed in school. Furthermore, the perspectives that people have in common and the primary context of students' socialization also show some potential interference upon the choices made by teachers in their daily practices. At last, we put forward a perspective of evaluation in which parameters and criteria are explicit, but may be carried out through different communication and language channels. By doing that, we will hopefully be contributing to the building of foundations of a school that is attentive both to the recognition and valuing of differences, as well as to the mitigation of inequality of access to the socially and historically produced knowledge.

\section{Keywords}

Evaluation - Curriculum - School knowledge - Teaching of Geography.

\section{Introdução}

No atual contexto de dissensos e disputas em torno do sentido da educação pública, a busca por uma escola justa constitui-se como um elemento central na definição das posições assumidas pelos professores diante das diferenças e desigualdades que conformam os ambientes escolares, especialmente em nosso país. De acordo com Dubet (2008), com a democratização do acesso à educação e o surgimento do fenômeno da escola de massa, o conceito de justiça escolar se complexificou. Para ele, "o projeto de construir uma escola justa, ou em todo caso a menos injusta possível, leva a articular e a combinar vários princípios de justiça” (DUBET, 2008, p. 114). 
Dessa forma, chama a atenção para os limites que a chamada igualdade meritocrática das oportunidades - baseada apenas nos méritos e dons pessoais - tem enquanto fundamento para o estabelecimento da justiça escolar. Ao princípio de justiça ligado à igualdade meritocrática das oportunidades, Dubet (2008) sugere o acréscimo e combinação de outras formas de igualdade, que integrem práticas equitativas que visem a oferecer mais e de maneira diferenciada àqueles que já chegam à escola em condições de vulnerabilidade social. Dentro desse contexto, parâmetros, critérios e processos de avaliação adquirem notável centralidade, pois permitem a gestão das aprendizagens em contextos onde as origens e pontos de partida dos estudantes são diferentes e desiguais. A avaliação das aprendizagens, dessa maneira, leva:

[...] o professor a observar mais metodicamente os alunos, a compreender melhor seus funcionamentos de modo a ajustar de maneira mais sistemática e individualizada suas intervenções pedagógicas e as situações didáticas que propõe, tudo isso na expectativa de otimizar as aprendizagens. (PERRENOUD, 1999, p. 89).

A avaliação, dentro desse cenário complexo de determinações, aponta para o problema do currículo e da construção dos conhecimentos escolares, o qual se situa em um importante ponto de tensionamento entre ações e políticas para a igualdade e as que se voltam para a valorização da diversidade dentro da escola. Em outras palavras, ao mesmo tempo em que deve estar atenta às diferentes formas de ver o mundo que caracteriza a diversidade que frequenta a escola, a atividade do professor também não pode deixar de mirar os objetivos e direitos de aprendizagem dos alunos, especialmente quando se leva em conta o papel que a escola desempenha na formação de sujeitos para a atuação em contextos amplos de vida, tanto em seus espaços imediatos de vivência como também no conjunto das redes e territórios de disputa que perpassam a construção de sua identidade enquanto cidadão do mundo.

0 presente texto tem o objetivo principal de pensar a atividade de avaliação das aprendizagens a partir da problematização em torno do conhecimento escolar. As reflexões que aqui se colocam, longe de ambicionarem esgotar a discussão sobre o tema, pretendem lançar luz à questão em pauta a partir do ponto de vista de autores que pensam o conhecimento na escola a partir de sua conexão com fatores que lhe são extrínsecos, ou seja, com o conjunto das contradições sociais que caracterizam os espaços de vivência dos sujeitos que a frequentam. Além de produções de autores como François Dubet, Michael Young e Basil Bernstein, serão também trazidas para o debate, a fim de ilustrar os pontos destacados, reflexões que resultaram de uma pesquisa de doutorado (STEFENON, 2017) que explorou a relação entre a recontextualização dos saberes disciplinares em diferentes contextos escolares e a (re)produção das desigualdades educacionais.

A pesquisa teve como interesse principal analisar o problema das desigualdades educacionais e do esvaziamento curricular da disciplina de geografia em diferentes contextos escolares. Para isso, de posse de categorias de análise que buscavam dar conta de caracterizar a prática pedagógica nesses contextos, foram feitas observações sistemáticas de aulas ministradas pela mesma professora de geografia em duas escolas públicas de 
perfis distintos da cidade de Curitiba/PR. Além disso, realizaram-se quatro entrevistas com professores da rede pública estadual do Paraná que atuam e/ou atuaram em escolas de realidades diversas, incluindo a professora observada. Dos resultados obtidos, foram selecionados aqueles que acreditamos contribuir para o debate em torno do papel da avaliação na definição dos ritos e na conformação do conhecimento escolares.

Diante disso, serão apresentados e discutidos no texto, primeiramente, elementos que podem contribuir para se refletir acerca do papel da escola na contemporaneidade e de aspectos em torno do tensionamento entre práticas de valorização da diversidade e de promoção da igualdade na escola. Por fim, depois de destacar elementos essenciais de referências teóricas que embasam o argumento aqui desenvolvido, pretende-se refletir a respeito dos critérios avaliativos e do uso de diferentes recursos e procedimentos de ensino e avaliação, a fim de explorar uma concepção de prática pedagógica atenta a esse cenário amplo de condicionantes que conformam a escola pública, especialmente no Brasil.

\section{As funções da escola e o papel do conhecimento}

As concepções em torno da função da escola na contemporaneidade, assim como outros temas de notável importância no campo da educação, não representam um território de convergência e consenso. Diferentes críticas em direção à força efetiva da escola na superação das contradições que conformam o mundo contemporâneo surgem de diferentes posições do campo intelectual. Tais críticas favorecem, a partir de pontos de vista diferentes, tratar a tese romântica de que a escola, por ela mesma, tem as condições necessárias para a inauguração de um mundo novo e mais justo.

Destaca-se aqui a posição de Young (2007) a respeito de algumas teses acerca das reais potencialidades e papéis da escola, especialmente as que são defendidas pelos reprodutivistas dos anos 60 e 70, por um lado, e os chamados pós-modernos, de outro. Para o autor, os reprodutivistas assumem uma "ideia de que o papel primordial das escolas nas sociedades capitalistas era o de ensinar à classe trabalhadora qual era o seu lugar" (YOUNG, 2007, p. 1289). A escola, para intelectuais como Althusser, Bourdieu, Bowles e Gintis, e Willis, como aponta o referido autor (YOUNG, 2007, p. 1289), tinha como função básica apenas a reprodução das relações desiguais de classe, o que limitaria determinantemente sua potencial capacidade para a transformação social.

Por outro lado, os já mencionados intelectuais pós-modernos, a partir de uma outra posição epistemológica, promovem uma crítica mais endereçada ao potencial do conhecimento escolar institucionalizado e disciplinar. Como um exemplo disso:

Em seu livro Vigiar e punir, Foucault (1995) agrupou escolas com hospitais, prisões e asilos, considerando-os como instituições de vigilância e controle, que disciplinavam alunos e normatizavam o conhecimento em forma de disciplinas escolares. [...] Para Foucault, não havia alternativa para a escolaridade como a vigilância, e a única coisa que os cientistas sociais e pesquisadores educacionais podiam fazer era criticar. (YOUNG, 2007, p. 1290). 
0 paradigma da pós-modernidade, em termos essenciais, ao questionar os tempos e espaços rígidos da escola, aponta para a valorização do pacto por uma escola construída, principalmente, sobre o fundamento dos conhecimentos que surgem do cotidiano dos estudantes. Em outras palavras, coloca-se a escola frente à diversidade, sendo sua função promover o desenvolvimento de aprendizagens definidas a partir dos contextos da vida de seus frequentadores.

Vale destacar também o posicionamento de Ivan Illich (1985), que vai muito além, defendendo a "desinstalação" da escola e a "desinstitucionalização" dos valores por ela transportados. Para este autor:

[...] a institucionalização de valores leva inevitavelmente à poluição física, à polarização social e à impotência psíquica três dimensões de um processo de degradação global e miséria modernizada. [...] Este processo de degradação se acelera quando necessidades não materiais são transformadas em demanda por mercadorias; quando saúde, educação, mobilidade pessoal, bem-estar, recuperação psicológica são definidos como resultados de serviços ou "tratamentos". (ILLICH, 1985, p. 16).

Ao defender uma "sociedade sem escolas", o autor aponta para a possibilidade da autoinstrução, onde os indivíduos de uma dada sociedade teriam a total liberdade para escolher quais "serviços de consulta a objetos de aprendizagem [...] e a educadores" (ILLICH, 1985, p. 89) seriam apropriados à educação que desejariam receber. Mesmo admitindo a sedução provocada pelo mundo da autonomia radical de Illich, totalmente desinstitucionalizado, parece-nos temeroso imaginar, por outro lado, uma condição em que sujeitos possam procurar serviços de educação que sirvam apenas para o reforço de seus próprios interesses, especialmente quando se considera o avanço do autoritarismo, do obscurantismo e da intolerância no atual momento em que a humanidade atravessa.

Mesmo diante de tudo isso, a partir dos pressupostos aqui assumidos, acredita-se que ao se admitir de maneira pura e radical as críticas realizadas por esses movimentos e autores, tende-se a desconsiderar outros importantes fatores que conformam a atividade comunicativa dentro da escola. Sendo assim, portanto, defende-se aqui a ideia de que a escola necessita assumir o papel de:

Organizar o desenvolvimento radical da função compensatória das desigualdades de origem, mediante a atenção e o respeito pela diversidade; [...] e provocar e facilitar a reconstrução dos conhecimentos, das disposições e das pautas de conduta que a criança assimila em sua vida paralela anterior a escola. Como diria Wood (1984, p. 239), preparar os alunos/as para pensar criticamente e agir democraticamente numa sociedade não-democrática. (PÉREZ GÓMEZ, 1998, p. 22).

Somando-se a essa perspectiva, Michel Young (2007) apresenta algumas ressalvas quanto ao enfraquecimento das fronteiras entre conhecimentos escolar e não-escolar, que se realiza com a justificativa de promover um currículo mais acessível aos diferentes grupos que frequentam a escola. Segundo o autor, a fragilização dessas fronteiras provoca um esvaziamento do currículo escolar e pode se tornar numa condição para a negação, 
sobretudo às camadas populares, de certo tipo de conhecimento capaz de lhe oferecer condições para o questionamento das contingências limitantes da vida e para a promoção da mudança. Dentro da perspectiva do autor, um currículo dessa natureza põe em xeque o princípio da equidade dentro da escola, sendo que é sua função precípua oferecer aos estudantes aquilo que ele chama de conhecimento poderoso. Nas palavras do autor:

Ao usar a palavra "conhecimento" em termos gerais, considero útil fazer uma distinção entre duas ideias: "conhecimento dos poderosos" e "conhecimento poderoso". 0 "conhecimento dos poderosos” é definido por quem detém o conhecimento. Historicamente e mesmo hoje em dia, quando pensamos na distribuição do acesso à universidade, aqueles com maior poder na sociedade são os que têm acesso a certos tipos de conhecimento; é a esse que eu chamo de "conhecimento dos poderosos". [...] Assim, precisamos de outro conceito, no enfoque do currículo, que chamarei de "conhecimento poderoso". Esse conceito não se refere a quem tem mais acesso ao conhecimento ou quem o legitima, embora ambas sejam questões importantes, mas refere-se ao que o conhecimento pode fazer, como, por exemplo, fornecer explicações confiáveis ou novas formas de se pensar a respeito do mundo. (YOUNG, 2007, p. 1294).

Seguindo nessa mesma direção, Dubet (2008) sugere, ao argumentar em favor do que considera uma "escola justa", que a escola necessita admitir a importância da chamada cultura comum, entendida como um conjunto mínimo de conhecimentos que deve ser oferecido aos diferentes sujeitos em aprendizagem, independentemente de seu contexto social e cultural. Para este:

De fato, é preciso mudar a norma da escola obrigatória, não para rebaixá-la, mas para fazer com que assuma um outro papel. Ao invés de fixá-la por um programa que poucos alunos conseguem acompanhar, é preciso definir o que cada um tem direito, estando claro que, uma vez alcançado esse limiar, nada impede de ir mais longe e mesmo muito mais longe. Em nome do que privar, de mais matemática, poesia ou tecnologia, os alunos que amam essas disciplinas, contanto que a manifestação de seu talento não se torne a norma e não afete o que é devido a todos? (DUBET, 2008, p. 78).

Parece evidente aqui certa tensão entre diferentes concepções de escola, as quais ou indicam que esta deve estar fortemente fundamentada nos saberes contextuais do aluno, ou que deve também estar atenta à cultura comum historicamente produzida, a qual é capaz de oferecer aos alunos um conhecimento que lhe trará condições de se situar no mundo para além dos limites de sua própria comunidade.

Dentro desse campo de reflexões acerca do conhecimento que se ensina na escola, inegavelmente, a diversidade é um ponto central a ser observado nos programas e currículos. Não há processo educativo sem levar em conta a realidade daqueles que a frequentam, suas angústias e necessidades. Contudo, faz-se aqui a ressalva que, conforme adverte Sacristán (1995), em sua face extrema, o currículo multicultural pode conduzir a escola em direção a certo relativismo de sua função social. De acordo com o autor: 
[...] tampouco seria realista, porque ingênuo, um relativismo cultural absoluto dentro do sistema escolar. Afinal de contas, a escolaridade não deixa de ser um meio de dotar de competências para a participação na vida social, econômica e cultural dominante, sempre melhorável. É óbvio que esta não está configurada por igual para todas as culturas. (SACRISTÁN, 1995, p. 106).

Ao falar da radicalização do paradigma da diversidade na escola, e levantar a hipótese da marginalização dos saberes conceituais institucionalizados, especialmente quando se considera a escola do pobre, Sacristán (1995) chama a atenção para a constituição de um possível obstáculo para que a escola cumpra sua tarefa de oportunizar aos diversos grupos sociais o acesso a determinados elementos da cultura comum institucionalizada e transformada em currículo, contribuindo assim para a produção e/ou reprodução das desigualdades educacionais.

\section{Bernstein e a avaliação}

A posição que aqui se assume, fundamentada em Basil Bernstein (1996; 1999), parte do pressuposto de que a escola também tem como função possibilitar aos sujeitos em formação o desenvolvimento de sua capacidade de manejar os contextos de comunicação que integram seu cotidiano. Para o referido autor, os saberes disciplinares especializados não constituem um tipo de saber superior àqueles compartilhados no mundo da experiência. Para Bernstein, cada tipo de texto comunicativo tem legitimidade em contextos específicos de produção: enquanto saberes consensuais - que são orientados pelo que Bernstein (1996) chama de códigos restritos -, regulam a comunicação em contextos informais, os saberes disciplinares especializados, regulados por códigos elaborados, permitem a compreensão das regras da comunicação em contextos referenciados e institucionalizados, como é o caso da escola, da academia e dos discursos e textos transportados pelos seus respectivos dispositivos pedagógicos.

A expressão texto, neste caso, pode designar qualquer representação "falada, escrita, visual, espacial ou expressa na postura ou na vestimenta” (BERNSTEIN, 1996, p. 243), ou ainda, no universo escolar pode indicar o próprio currículo dominante, as práticas dos professores, como também qualquer produção/representação elaborada pelos estudantes. Os textos, portanto, são tomados como a dimensão visível da comunicação, que é orientada e legitimada por uma espécie de gramática profunda - o código, propriamente dito - que corresponde à dimensão invisível que subjaz ao conteúdo da comunicação. Os códigos de comunicação restritos e elaborados, portanto, dentro da teoria bernsteiniana são princípios que regulam a produção dos textos nas interações humanas que ocorrem em diferentes contextos comunicativos.

Isso significa dizer que, ao mesmo tempo, os códigos possibilitam a identificação das fronteiras entre os contextos de comunicação, como também as regras que regulam a comunicação dentro dos contextos. Em outras palavras:

Na orientação restrita, os significados são particularistas, dependentes do contexto e têm uma relação direta com uma base material específica. Na orientação elaborada, os significados são 
universalistas, relativamente independentes do contexto e têm uma relação indireta com uma base material especifica. (MORAIS; NEVES, 2007, p. 116).

De acordo com o autor, inclusive, é possível tratar dessa gramática profunda que orienta a produção dos textos em termos de "códigos de classe". Em suas palavras:

Os códigos de classe e suas modalidades são gramáticas semióticas específicas, as quais regulam a aquisição, a reprodução e a legitimação de regras fundamentais de exclusão, inclusão e apropriação pelas quais e através das quais os sujeitos são seletivamente criados, posicionados e oposicionados. (BERNSTEIN, 1996, p. 72).

Ao relacionar a aquisição dos códigos à posição dos sujeitos no espectro amplo das relações sociais de classe, argumenta que determinados indivíduos trazem de seu contexto primário de socialização certa versão da prática pedagógica que se efetua na escola. Isso porque esses sujeitos frequentam contextos de comunicação onde os códigos implícitos tendem a ser mais universalistas e especializados, ou seja, convivem em ambientes com maior presença de interlocutores capazes de reconhecer formas elaboradas de comunicação. 0 currículo escolar, nesse sentido, passa a ser visto como um texto privilegiante que tende a fazer mais sentido a esses sujeitos inseridos em relações sociais e de comunicação que mais se aproximam ao que é privilegiado na escola. Diante disso, "o sucesso ou o fracasso [escolar] são uma função do currículo dominante da escola, o qual atua seletivamente sobre aqueles que podem adquiri-lo" (BERNSTEIN, 1996, p. 166-167).

Ao se admitir o papel da classe social na produção das desigualdades de aquisição dos códigos elaborados - os quais possibilitariam maior mobilidade na escolha dos papéis sociais, independentemente das condições de origem dos sujeitos -, aponta-se para uma configuração específica da função social da escola na contemporaneidade. Nesses termos, seria sua função oferecer condições para que estudantes possam manejar diferentes contextos de comunicação, mediante a aquisição de códigos que lhes permitam reconhecer a validade e a legitimidade dos textos em diversas situações de interação, por meio da identificação das regras que a regulam.

Dessa maneira, enquanto na rua, comunidade e em outros ambientes cotidianos predominam formas de comunicação regidas por códigos restritos; na escola, trabalho, academia - dentre outros ambientes que não fazem parte do contexto imediato da vida dos sujeitos -, são os códigos elaborados que são privilegiados na comunicação. A passagem de um para outro, como também, o uso contextualizado de cada um desses códigos é o que caracteriza um bom manejo de contextos.

Diante do pressuposto da necessidade de se pautar a construção dos currículos escolares em parâmetros de conhecimento validados social e historicamente, os quais permitem aos sujeitos desenvolver sua capacidade de manejar diferentes contextos de comunicação, os processos de gestão das aprendizagens realizados pelo professor na sala de aula, materializados nos mecanismos de avaliação, assumem um papel central. É na avaliação que essa tensão entre valorização da diversidade e promoção da igualdade adquire seu mais alto grau de objetividade, exigindo do profissional a sensibilidade 
necessária para permitir aos sujeitos a liberdade para se expressar sem privá-los dos saberes que possibilitarão sua compreensão ampla e crítica da realidade.

0 texto pedagógico, ou seja, o conteúdo da comunicação na sala de aula é estruturado a partir de um conjunto de regras, as quais Bernstein (1996) chama de dispositivo pedagógico. Este dispositivo "fornece a gramática intrínseca do discurso pedagógico" (BERNSTEIN, 1996, p. 254) e é regulado pelas regras distributivas, as regras recontextualizadoras e as regras de avaliação, que têm uma relação de interdependência entre si.

As regras distributivas são um conjunto de normas que estabelecem as fronteiras entre as diferentes formas de conhecimento, conformando sua distribuição entre os sujeitos de diferentes classes sociais, determinando o acesso - muitas vezes desigual - aos discursos especializados. Em outras palavras, tais regras definem o que pode ser ensinado e a quem algo poderá ser ensinado, com base em expectativas que, muitas vezes, são definidas a partir das origens sociais dos sujeitos envolvidos no processo educativo. As regras recontextualizadoras, por sua vez, são aquelas "que constituem o discurso pedagógico" (BERNSTEIN, 1996, p. 259), em si. Para o autor, os diversos discursos específicos das disciplinas são relocados em novos contextos e são refocalizados nesse processo, em que discursos especializados dos diferentes campos são sempre embutidos em uma lógica de ordem regulativa com suas intencionalidades próprias.

As regras de avaliação, as quais nos interessam mais centralmente neste momento, dizem respeito à própria prática pedagógica, ou seja, são compostas por procedimentos, ritmos de aprendizagem, sequenciamentos e critérios de avaliação, os quais estabelecem o controle da prática educativa. Isso quer dizer que as regras de avaliação definem a validade e a legitimidade dos textos que são produzidos e/ou reproduzidos no âmbito da aula. Ao promoverem essa regulação, as regras avaliativas definem as relações de comunicação no interior da prática pedagógica e, por essa razão, convertem-se em um mecanismo de modelação dos comportamentos e dos ritos presentes nos diversos contextos educativos. (BERNSTEIN, 1996).

Dependendo da situação e dos pressupostos que orientam a construção da aula e dos procedimentos de avaliação, tais regras podem ser consideradas explícitas. Isso quer dizer que tendem a ser claramente informadas aos adquirentes e fundamentadas em critérios de avaliação que são mais fortemente controlados pelo professor. Por outro lado, as regras de avaliação também podem assumir um caráter mais implícito, ou seja, derivam de relações mais abertas entre transmissores e adquirentes. Nesse caso, a definição dos ritmos e fronteiras entre os diferentes discursos, assim como a validade deles na produção dos textos pedagógicos, tende a sofrer maior influência dos adquirentes, ou seja, dos estudantes.

Com base nesse modelo, pode-se inferir que os critérios de avaliação interferem diretamente na determinação dos produtos da prática pedagógica. Conforme destacam Morais et al. (2004), a aprendizagem científica depende de critérios de avaliação explícitos, pois os estudantes precisam saber com clareza o que se espera do desempenho deles, já que aquilo que embasa a validade do texto, nesse caso, é um conjunto extrínseco de saberes epistemologicamente referenciados. Sendo assim, a validação e legitimação dos textos elaborados pelos estudantes dependem da explicitação desses critérios pelo professor, o qual desempenha assumida centralidade na sua legitimação. 
Ao esconder os critérios ou não os fundamentar em parâmetros claros e explícitos, tende-se a promover uma prática pedagógica descolada de códigos elaborados de comunicação, já que os textos e produções dos estudantes terão validade sem a necessidade de estarem pautados em algo objetivamente definido ou em um conjunto de saberes disciplinares e referenciados. Essa condição, de acordo com a teoria bernsteiniana, poderia configurar-se como uma restrição das experiências educativas oferecidas na escola, reproduzindo-se desigualdades educacionais.

\section{Reflexões com base na realidade investigada}

As reflexões construídas a partir da pesquisa de doutorado utilizada aqui como um dos fundamentos para a elaboração deste ensaio indicam que a explicitação dos critérios de avaliação assumem diferentes níveis nas escolas investigadas. Tais níveis variam em função das fortes limitações que as escolas apresentam para lidar com o forte papel exercido pelo contexto primário de socialização dos estudantes na conformação da prática pedagógica.

Das duas escolas de perfis distintos que foram observadas ao longo da pesquisa, uma delas, a qual chamaremos aqui de colégio X, é considerada pela comunidade como uma escola pública de excelência, enquanto a outra escola, aqui designada como colégio Y, por mais que seja uma importante e tradicional instituição de ensino, não desfruta do mesmo estigma. 0 perfil distinto das duas escolas pode ser atestado ao se acessar os resultados dos alunos no Exame Nacional do Ensino Médio, nos quais se verifica que a pontuação média (entre todas as áreas de avaliação desse exame) foi de 736,00 para 0 colégio X e de 592,94 para o colégio Y (BRASIL, 2016).

Para além desse aspecto quantitativo, o colégio $X$ tem seleção de entrada para estudantes, um regime diferenciado de financiamento e um projeto bastante amplo de aulas e atividades em contraturno, como cursos de línguas estrangeiras, espaços de discussão, clubes de leitura, oficinas de arte, clube de astronomia, esportes diversos, dentre outras. Tais tipos de atividades não são oferecidas pelo colégio Y. A seleção desses dois colégios para o estudo ocorreu tanto por conta da constatação desses perfis distintos, como também, pelo fato de uma mesma professora de geografia atuar nas duas realidades. Isso permitiu o empreendimento da análise do conhecimento compartilhado nas aulas de maneira a focalizar, com maior detalhe, os fatores contextuais que interferem no processo de estruturação dos discursos curriculares.

A pesquisa demonstrou que os estudantes do colégio $\mathrm{X}$ tendem a ser de famílias em que os responsáveis têm ocupações profissionais que demandam maior nível de instrução acadêmica. Isso resulta em um mais amplo conjunto de expectativas e de cobranças que os estudantes estabelecem para si, o que reflete sobre a leitura que o professor realiza sobre tais expectativas. A definição do nível de explicitação dos critérios de avaliação, conforme verificou-se a partir dos resultados da referida pesquisa, é também um produto da ação direta do professor ao considerar esse conjunto das expectativas de futuro envolvidas na prática pedagógica. Isso fica claro quando se consideram as palavras da professora entrevistada, que atua nos dois colégios investigados. Segundo ela, 
Aqui no Colégio X eles questionam tudo. Você devolve a avaliação pra eles e eles vêm perguntar por que não acertaram. Eles brigam às vezes por um décimo, dois décimos, eles querem as melhores notas, mas querem o aprendizado também. Eles reclamam se o professor não ensina, se eles não entendem... eles são críticos. E lá no Colégio Y você entrega a prova e fica esperando: pessoal, alguma dúvida, alguma coisa que não entenderam? venham perguntar! Não! Eles pedem pra passar o gabarito da prova no quadro, pois eu peço que eles façam a reescrita da prova pra eles poderem fazer, pra terem a nota lá, mas não é pra pensar, questionar. 0 aluno, quando vem questionar a nota aqui (no Colégio X) ele vem questionar a questão. Por que não estava certo aqui? Por que eu errei? Ele vem, ele também quer a nota, mas tá questionando também a correção. E lá não. Lá é a nota pela nota. Claro, aumentar a nota eles querem, mas lá é só pra aumentar. E quando questionam! Normalmente é: pessoal somem a prova pra ver se a professora errou alguma coisa, mas nem isso. Eles são muito apáticos nesse sentido. (Entrevista, professora A).

0 reconhecimento da legitimidade do rito da avaliação por parte dos estudantes, conforme descrito pela entrevistada, foi considerado como outro fator importante na explicitação dos critérios. Durante uma das aulas observadas no colégio X, por exemplo, ao explorar um detalhe acerca da temática do vulcanismo, a professora é interrompida por uma das alunas, que sugere que a professora utilize o tempo da aula para tratar apenas dos assuntos que iriam, efetivamente, "cair na prova”, haja vista que em sua apresentação a docente afirmou que esse detalhe não seria cobrado diretamente na avaliação. Essa situação, que representa uma amostra da realidade investigada, permite considerar que o interesse maior dos estudantes no processo de legitimação dos textos produzidos por eles, portanto, passa também pela expectativa de seu sucesso nos testes, tanto ao longo da carreira escolar como fora dela. Dessa maneira, pode-se argumentar que, mesmo destacando-se o interesse dos estudantes desse colégio pela aprendizagem conceitual, o reconhecimento da legitimidade das regras do jogo pedagógico, como também sua expectativa pelo sucesso com as notas e na classificação imposta pelo sistema escolar, coloca-os numa condição de maior interesse pela explicitação dos critérios da avaliação.

Por outro lado, esse conjunto de expectativas parece não se colocar de forma tão central quando se analisam os relatos das observações realizadas no colégio $\mathrm{Y}$, onde verificou-se que:

Muitos alunos não fizeram a atividade proposta pela professora e apresentam muitas desculpas, em tom de brincadeira, demostraram certa despreocupação com as notas. Professora marca prova escrita para próxima semana. Diz que o conteúdo (e escreve no quadro também) refere-se ao capítulo 5 do livro, da pg. 92 a 109. Não disse ou trabalhou o que seria efetivamente cobrado, apenas informou as páginas e capítulo que tratam do tema. (Relato de campo, colégio Y).

Com base no que se destaca, portanto, a análise dos resultados da pesquisa sugere que o estabelecimento dos critérios de avaliação, assim como a própria natureza da comunicação pedagógica, tende a receber forte influência dos adquirentes. Em alguns casos, o referente objetivo da avaliação desloca-se do corpo de saberes disciplinares em direção ao que o próprio aluno considera verdadeiro e válido, a partir dos saberes 
de sua própria experiência. Essa flexibilização dos critérios de avaliação, ou ainda, a flexibilização das fronteiras entre conceitos científicos e conceitos espontâneos, conforme terminologia proposta por Vygotsky (2008), pode se tornar num potencial gerador de esvaziamento do currículo, concorrendo para a (re)produção das desigualdades que têm origem fora da escola.

Ao se olhar para o caso dos saberes da geografia, as observações e entrevistas realizadas durante a pesquisa demonstraram que ao se perder de vista o referencial da disciplina, os conteúdos da aula tendem a se aproximar de um perfil mais descritivo e informativo, com uma menor presença de conflito cognitivo. Um exemplo disso foi uma sequência de atividades acerca do mesmo tema - estrutura interna da Terra - observada durante a pesquisa empírica em turmas de $1^{\circ}$ ano de Ensino Médio nos dois colégios investigados. Enquanto no colégio $\mathrm{Y}$ as atividades de fixação dos conteúdos se basearam em atividades de pintura de figuras e no trabalho de nomear as estruturas e camadas da Terra; no colégio $\mathrm{X}$ foram utilizadas questões de vestibular com diversos níveis de complexidade, exigindo maior envolvimento cognitivo dos estudantes e a mobilização de processos de raciocínio mais elaborados.

Neste ponto, percebe-se que as atividades mobilizam diferentes competências cognitivas, as quais se relacionam com diferentes formas de expressão textual. Os critérios para avaliação dos diversos textos produzidos, então, são adaptados às diferentes expectativas de aprendizagem, tanto dos professores como também dos próprios estudantes. Essa adaptação dos critérios pôde ser verificada, também, por meio da entrevista concedida pelo professor B, na qual afirma que em seu contexto de trabalho procura:

[...] avaliar se ele conseguiu perceber dentro do conteúdo que foi passado e ensinado, como esse conteúdo pode ajudá-lo de alguma forma na vida dele dentro de um contexto de aplicação prática que está sendo cobrado numa avaliação e se ele conseguiu receber a informação. [...] Então eu procuro muitas vezes, eu extraio o máximo de uma resposta numa prova, incentivando até o aluno através da nota que ele está tirando na prova, dando numa questão que vale meio ponto eu consigo extrair muitas vezes até 0,1 da resposta, mesmo que ela não atenda plenamente o que está sendo solicitado, mas que tenha alguma coisa relativa aquilo que foi perguntado. Então a gente procura considerar o máximo, ou o mínimo do conhecimento que ele conseguiu absorver. (Entrevista, professor B).

Os saberes cotidianos dos estudantes, em situações como apontadas pelo professor entrevistado, tendem a ser considerados como legítimos no processo de avaliação independentemente de estarem balizados em ferramentas conceituais provenientes do campo do conhecimento disciplinar especializado. Ao considerar condições contextuais onde os estudantes possuem perfis diferentes entre si, como é o caso dos dois colégios observados durante o trabalho de campo, tal flexibilização de critérios de avaliação tende a produzir reflexos diretos sobre o código implícito à comunicação pedagógica, ou sobre a natureza da relação com o saber que cada um desses grupos apresenta. Isso exige do professor uma profunda sensibilidade para identificar, interpretar e valorizar as diferenças e desigualdades em seus contextos de atuação, a fim de gerir as aprendizagens de uma maneira que promova o alcance de seus objetivos. 
Dentro desse cenário de complicações, parece útil a distinção entre duas dimensões fundamentais da prática pedagógica, conforme proposta por Young (2011), a fim de organizar e dar mais consciência à essa prática.

A primeira ideia diz respeito a currículo, que se refere ao conhecimento que um país considera importante que esteja ao alcance de todos os estudantes. A segunda ideia diz respeito à pedagogia, que, em contraste, se refere às atividades dos professores para motivar os alunos e ajudá-los a se engajarem no currículo e torná-lo significativo. (YOUNG, 2011, p. 612).

Para Young $(2007$; 2011), por mais que essas duas dimensões da prática pedagógica sejam interdependentes entre si, é importante manter certo grau de classificação entre elas a fim de dar visibilidade ao que o aluno deve aprender, e também, a tudo aquilo que o aluno traz consigo como elementos de sua experiência. Ao defender uma aprendizagem conceitual na escola, onde os saberes disciplinares especializados deveriam ser a base da construção dos currículos, o autor defende uma autonomia irrestrita do professor no que tange ao planejamento pedagógico de suas aulas, pois somente o professor tem a competência, dentro das diferentes instâncias dos sistemas de educação, de promover a motivação efetiva dos estudantes para aprender, e assim possibilitar o encontro entre os - ou a reconstrução dos - conceitos científicos e espontâneos, processo que é visto por muitos (VYGOSTKY, 2008; BERNSTEIN, 1996; DUBET, 2008; YOUNG ; 2011; CAVALCANTI, 1998; CASTELLAR, 2007) como a função precípua da escola.

No caso da geografia, essa reconstrução dos saberes espontâneos e a eventual promoção do pensamento conceitual durante as aulas tende a permitir uma ampliação das formas de se ver o mundo (CAVALCANTI, 1998), mediante o oferecimento de um currículo multiescalar. Isso significa dizer que, ao buscar referências em saberes disciplinares especializados, a geografia escolar pode contribuir para que o estudante compreenda os problemas de sua comunidade em relação ao que acontece fora dela, ou seja, em suas múltiplas escalas de determinação. Essa capacidade de transferência das explicações é uma característica evidente do processo de generalização promovido pelo pensamento conceitual.

Ao retomar aqui a defesa da centralidade do professor na interpretação dessas diferenças e desigualdades a fim de estabelecer procedimentos práticos para o seu enfrentamento, há que se considerar que a autonomia do professor perante a definição dos ritos e da mensagem a ser transmitida na aula nunca é absoluta. De certa forma, essa ideia vai ao encontro da proposição de Sacristán (1991, p. 75) acerca da "irresponsabilidade relativa" do professor perante a prática pedagógica, em que nem sempre esse sujeito, por ele mesmo, tem as condições necessárias para produzir as mudanças ou os ritos adequados ao que se considera uma boa prática pedagógica. Outros elementos e fatores interferem nesse processo e impõem limites e obstáculos à atuação docente.

No que se refere à realidade observada durante a pesquisa, a natureza das expectativas dos sujeitos que frequentam a escola, o conjunto das atividades extra aula que são oferecidas aos estudantes, a estrutura de apoio que os professores possuem, os equipamentos disponíveis na escola, e as limitações de tempo disponível, permitem a ocorrência de ambientes diferenciadamente organizados, os quais atuam diretamente sobre essa "irresponsabilidade relativa" dos docentes. Estruturas mais adequadas de 
trabalho, as quais dependem diretamente de uma política de investimentos na escola feita com seriedade e perseverança, como o caso do colégio X parece ilustrar, tendem a se apresentar como condições necessárias para a constituição de um terreno fértil para que a prática dos professores possa assumir a flexibilidade necessária para o tratamento da diversidade que aviva a escola.

Mesmo considerando tais dificuldades, defende-se a definição de um campo de ação possível para o professor que, dentro das condições não ideais que lhe são oferecidas, poderá estabelecer níveis de exigência conceitual em suas aulas e avaliações capazes de lidarem com as desigualdades que caracterizam a escola, mediante à explicitação de critérios, diversificação de canais de comunicação e de expressão do aluno, e ações que promovam seu envolvimento com a aula e a escola. Ao flexibilizar a dimensão pedagógica de sua prática cotidiana, o professor terá condições mais concretas de lidar com a diferença, estabelecendo percursos de construção do conhecimento mais individualizados e contextualizados à realidade dos diferentes estudantes. A partir daí, seguindo na esteira das referências teóricas e empíricas que fundamentam este argumento, o professor será capaz de construir critérios de avaliação compatíveis com uma concepção de escola que tenha o conhecimento científico como seu pilar de sustentação, a qual poderá cumprir sua função de oferecer os conhecimentos necessários para a vida em comunidade de maneira crítica e comprometida, tanto com a construção de uma cidadania profunda e inclusiva quanto com a busca pela mitigação das desigualdades e contradições que fundam o mundo capitalista.

\section{Considerações finais}

Os pressupostos aqui defendidos apontam para a conformação de uma escola que tem nos saberes disciplinares e conceituais o referente central para a construção dos currículos. Ao assim se definir, a instituição escolar passa a depender diretamente da clareza e da explicitação das regras e critérios de avaliação, a fim de que se promovam aprendizagens que permitam a aquisição de ferramentas amplas e críticas para a compreensão do mundo.

A construção do pensamento conceitual na escola, conforme sugere Vygotsky (2008), é um processo em que ocorrem novas aprendizagens mediante à permissão do encontro entre conceitos espontâneos e científicos. Enquanto os primeiros se referem a um movimento de construção de conhecimento fundamentado nas vivências dos sujeitos ao longo de suas trajetórias cotidianas, os conceitos científicos são aqueles produzidos em ambientes controlados por regras e procedimentos que permitem a liberação do pensamento de uma base material concreta, ou seja, permitem a ampliação crítica acerca daquilo que se conhece. Ao evidenciar o caráter ascendente dos saberes consensuais e o viés descendente dos conceitos científicos, Vygotsky chama a atenção ao fato de que tal encontro tem um potencial inerente à mudança, pois é a partir da reflexão livre daqueles que se sujeitam a esse processo que os novos saberes são reconstruídos e colocados a serviço da solução de problemas objetivos que têm origem na experiência concreta dos sujeitos. Em outras palavras: 
A formação de conceitos é o resultado de uma atividade complexa, em que todas as funções intelectuais básicas tomam parte. No entanto, o processo não pode ser reduzido à associação, à atenção, à formação de imagens, à inferência ou às tendências determinantes. Todas são indispensáveis, porém insuficientes sem o uso do signo, ou palavra, como o meio pelo qual conduzimos as nossas operações mentais, controlamos seu curso e as canalizamos em direção à solução do problema que enfrentamos. (VYGOTSKY, 2008, p. 72-73).

Ao destacar a importância do processo de formação dos conceitos no desenvolvimento das funções intelectuais mais complexas da mente humana, regras e critérios explícitos de avaliação, juntamente com ferramentas de avaliação que permitam o uso de diferentes linguagens de expressão e de comunicação na escola, passam a colaborar nessa difícil tarefa de valorizar os saberes consensuais trazidos pelos alunos sem comprometer as novas aprendizagens conceituais, condição imprescindível para o desenvolvimento intelectual dos estudantes.

0 papel da avaliação na gestão dessas novas aprendizagens, portanto, busca ultrapassar sua perspectiva meramente classificatória, apontando para sua função de mediação da prática educativa - em que a proximidade e o diálogo entre professor e estudantes permitem a descoberta construtiva de soluções para o aperfeiçoamento dos processos de ensino e aprendizagem -, e também na direção de efetivar seu papel formativo e diagnóstico, permitindo o reconhecimento dos saberes prévios dos estudantes e de seus contextos de vida e pensamento, como também, constituindo-se em um instrumento de controle dos processos de ensino e aprendizagem que indique, efetivamente, percursos mais contextualizados aos diferentes estudantes.

Sendo assim, concorda-se aqui com a ideia de que "não se poderia separar a reflexão sobre a avaliação de um questionamento mais global sobre as finalidades da escola, das disciplinas, do contrato pedagógico e didático e dos procedimentos de ensino e de aprendizagem" (PERRENOUD, 1999, p. 168). Ao manter vivo o debate na escola acerca do papel que essa exerce para os diferentes sujeitos que a frequentam, criam-se condições para a promoção de um processo de avaliação comprometido mais com a formação do que com a simples classificação dos estudantes.

Diante desse conjunto de posicionamentos, espera-se contribuir para a construção de fundamentos necessários para que a escola realize de maneira segura a travessia desse momento caótico que a humanidade enfrenta, produzido pelo acirramento das tensões e dos autoritarismos em diferentes dimensões da vida, das quais se destacam a política, os conflitos territoriais, a fragilidade das democracias, a emergência de fundamentalismos de toda ordem, dentre outros.

Tudo isso coloca sobre a escola a responsabilidade de bem tratar tanto o passado, como o futuro, a fim de proporcionar aos jovens subsídios efetivos para a compreensão de sua situação no mundo e para que possam agir nele de maneira ampla e crítica. Dessa maneira, entendemos que uma escola, verdadeiramente preocupada com esse contexto caótico de transições e incertezas, deve ser um canal para dar vazão a novas utopias, a fim de construir alternativas que estejam efetivamente conectadas às necessidades e esperanças de um futuro mais democrático, plural e inclusivo. 


\section{Referências}

BERNSTEIN, Basil. A estruturação do discurso pedagógico: classes, código e controle. Petrópolis: Vozes, 1996.

BERNSTEIN, Basil. Vertical and horizontal discourse: an essay. British Journal of Sociology of Education, London, v. 20, n. 2, p. 157-173, 1999.

BRASIL. Instituto Nacional de Estudos e Pesquisas Educacionais Anísio Teixeira. Enem por escola. Brasília, DF: INEP, 2016. Disponível em: <http://portal.inep.gov.br/web/enem/enem-por-escola>. Acesso em: 07 nov. 2016.

CASTELLAR, Sonia Maria Vanzella. A psicologia genética e a aprendizagem no ensino de Geografia. In: CASTELLAR, Sonia Maria Vanzella (Org.). Educação geográfica: teorias e práticas docentes. São Paulo: Contexto, 2007. p. 38-50

CAVALCANTI, Lana de Souza. A geografia e a construção de conhecimentos. Campinas: Papirus, 1998.

DUBET, François. 0 que é uma escola justa? A escola das oportunidades. São Paulo: Cortez, 2008.

ILLICH, Ivan. Sociedade sem escolas. Petrópolis: Vozes, 1985.

MORAIS, Ana Maria; NEVES, Isabel Pestana. A teoria de Basil Bernstein: alguns aspectos fundamentais. Práxis Educativa, Ponta Grossa, v. 2, n. 2, p. 115-130, 2007.

MORAIS, Ana Maria; NEVES, Isabel Pestana, PIRES, Delmina. The what and the how of teaching and learning: going deeper into sociological analysis and intervention. In: MULLER, Johan; DAVIES, Brian; MORAIS Ana Maria (Org.). Thinking with Bernstein, working with Bernstein. London: Routledge, 2004. p. 75-90

PÉREZ GÓMEZ, Angel. As funções sociais da escola: da reprodução a reconstrução crítica do conhecimento e da experiência. In: SACRISTÁN, José Gimeno; PÉREZ GÓMEZ, Angel. Para compreender e transformar o ensino. São Paulo: Artmed, 1998. p. 13-26.

PERRENOUD, Phillip. Avaliação: da excelência à regulação das aprendizagens - entre duas lógicas. Porto Alegre: Artes Médicas Sul, 1999.

SACRISTÁN, José Gimeno. Currículo e diversidade cultural. In: SILVA, Tomaz Tadeu; MOREIRA, Antônio Flávio Barbosa (Org.). Territórios contestados: o currículo e os novos mapas políticos e culturais. Petrópolis: Vozes, 1995. p. 82-113.

STEFENON, Daniel Luiz. Desigualdades educacionais e esvaziamento curricular: um estudo a partir do caso da recontextualização dos saberes geográficos na escola. 2017. Tese (Doutorado em Educação) Faculdade de Educação, Universidade de São Paulo, São Paulo, 2017.

VYGOSTSKY, Lev Semyonovich. Pensamento e linguagem. São Paulo: Martins Fontes, 2008. 
YOUNG. Michael. 0 futuro da educação em uma sociedade do conhecimento: 0 argumento radical em defesa de um currículo centrado em disciplinas. Revista Brasileira de Educação, Rio de Janeiro, v. 16, n. 48, p. 609-623, 2011.

YOUNG. Michael. Para que servem as escolas? Educação \& Sociedade, Campinas, v. 28, n. 101, p. $1287-$ 1302, 2007.

Recebido em: 07.11.2018

Revisado em: 27.04.2019

Aprovado em: 25.06.2019

Daniel Luiz Stefenon é doutor em educação pela Faculdade de Educação da Universidade de São Paulo (USP) e mestre em geografia pela Universidade Federal do Paraná (UFPR). Docente do Departamento de geografia e do Programa de Pós-Graduação em Educação da Universidade Estadual do Centro-Oeste (Unicentro), campus de Irati/PR, Brasil.

Sonia Maria Vanzella Castellar é professora titular da Faculdade de Educação da Universidade de São Paulo (USP) e do Programa de Pós-Graduação em Geografia Humana da Faculdade de Filosofia, Letras e Ciências Humanas da USP. Bolsista produtividade CNPq 2. Doutora em geografia e mestre em didática pela USP. 